\title{
FORMULATION AND CHARACTERIZATION OF FLOATING BEADS OF ANTIBIOTIC BY EMULSION GELATION TECHNIQUE
}

\author{
KHALIFA MY*, SHAIKH SIRAJ N \\ Department of Pharmaceutics, Ali-Allana College of Pharmacy, Akkalkuwa, Nandurbar, Maharashtra, India. \\ Email: khalifa4517@gmail.com
}

Received: 22 January 2018, Revised and Accepted: 14 March 2019

\section{ABSTRACT}

Objective: The study aims at formulation and characterization of floating hydrogel beads of cefdinir for improving its bioavailability.

Methods: Cefdinir is broad-spectrum, oral, third-generation cephalosporin antimicrobial agent active against Gram-positive and Gram-negative bacteria. The floating hydrogel beads of cefdinir were formulated with polymers such as sodium alginate and sodium carboxymethyl cellulose by emulsion gelation technique using olive oil/castor oil. The beads were evaluated for surface morphology, bead size, entrapment efficiency, floating characteristics, in vitro swelling, in vitro drug release, and stability studies.

Results: On the basis of evaluation, all the beads show good swelling up to $12 \mathrm{~h}$ in $0.1 \mathrm{~N}$ hydrochloric acid. The swelling was followed by values in order of vegetable oil > mineral oil in case of emulsion gelation method. Scanning electron microscopy study shows that beads were spherical in shape. Comparing all the formulations, formulation FB12 was considered as optimized formulation which shows $\%$ yield $94.06 \pm 0.11, \%$ floating $87.28 \pm 0.90$, in vitro drug release 94.68 , and also stable in stability studies.

Conclusion: From the findings, it may be concluded that cefdinir-loaded floating beads were successfully prepared and proved to be useful for the better bioavailability and patient compliance for enhanced antimicrobial activity.

Keywords: Cefdinir, Emulsion gelation, Floating, Sodium carboxymethyl cellulose, Sodium alginate, Olive oil, Castor oil.

(C) 2019 The Authors. Published by Innovare Academic Sciences Pvt Ltd. This is an open access article under the CC BY license (http://creativecommons. org/licenses/by/4. 0/) DOI: http://dx.doi.org/10.22159/ajpcr.2019.v12i5.32103

\section{INTRODUCTION}

Oral delivery of drugs is by far the most preferable route of drug delivery due to the ease of administration, patient compliance, and flexibility in formulation [1]. From immediate release to site-specific delivery, oral dosage forms have really progressed [2]. However, it is a well-accepted fact that it is difficult to predict the real in vivo time of release with solid, oral controlled release dosage forms. Thus, drug absorption in the gastrointestinal tract (GIT) may be very short and highly variable in certain circumstances [3].

One of the most feasible approaches for achieving a prolonged and predictable drug delivery profile in the GIT is to control the gastric residence time. Dosage forms with a prolonged gastroretentive dosage forms will provide us with new and important therapeutic options [4]

Nowadays, alginate gel beads become post-acceptable vehicle for drug delivery since it is cost-effective, biodegradable, simple process [5]. Floating is the most acceptable approach of gastroretentive drug delivery system (GRDDS). Floating approach is available in single as well as multiparticulate forms such as beads, microspheres, and pellets [6]. Beads spread out more uniformly in the GIT, thus avoiding exposure of the mucosa locally to high concentration of drug [7]. Beads are small, solid, and free-flowing particulate carriers containing dispersed drug particles either in solution or crystalline form. Spherical beads of approximately $2.5 \mathrm{~mm}$ in diameter [8].

Cefdinir is a broad-spectrum, oral, third-generation cephalosporin antimicrobial agent active against Gram-positive and Gram-negative bacteria. It is used in treatment of acute chronic bronchitis, rhinosinusitis, pharyngitis, etc. Cefdinir is having half-life of $1.5 \mathrm{~h}$ with oral bioavailability 20-30\%. Cefdinir is better absorbed from the upper part of the GIT [9].
Therefore, in the present study, an attempt will be made to design and evaluate GRDDS of cefdinir with a view to enhance its bioavailability, duration of action, and convenience of administration in the form of hydrogel beads as floating system leading to improved patient compliance.

\section{MATERIALS AND METHODS}

\section{Materials}

Cefdinir was purchased from Rajesh Chemicals, Mumbai (India), Sodium alginate, Sodium carboxy methyl cellulose (CMC), Calcium chloride, Aluminum chloride, Calcium Vegetable oil, mineral oil, (SD Fine Chem Ltd., Mumbai). All other chemicals were of analytical grade.

Methods

Standard calibration curve of cefdinir in $0.1 \mathrm{NHCL}(\mathrm{pH}$ 1.2) buffer solutions

Preparation of stock solution

Accurately weighed $10 \mathrm{mg}$ of cefdinir was dissolved in small amount of $0.1 \mathrm{~N} \mathrm{HCL} \mathrm{(pH} \mathrm{1.2),} \mathrm{and} \mathrm{the} \mathrm{volume} \mathrm{was} \mathrm{then} \mathrm{made} \mathrm{up} \mathrm{to} 100 \mathrm{ml}$ with the same to obtain a concentration of $100 \mu \mathrm{g} / \mathrm{ml}$.

Preparation of working standard solution

From the above solution, aliquots of $0.3,0.6,0.9,1.2,1.5$, and $1.8 \mathrm{ml}$ were transferred to a series of $10 \mathrm{ml}$ volumetric flask and diluted up to the mark with $0.1 \mathrm{~N} \mathrm{HCL}(\mathrm{pH} \mathrm{1.2)}$ to give $3,6,9,12,15$, and $18 \mu \mathrm{g} / \mathrm{ml}$. Absorbance was measured spectrophotometrically at $287 \mathrm{~nm}$ against blank using Shimadzu Ultraviolet (UV) Spectrophotometer.

\section{Method of floating bead formulation}

Emulsion gelation technique

Solutions of sodium alginate and sodium CMC were prepared by stirring in distilled water. Cefdinir and olive oil/castor oil were added to the solution. 
Each mixture with total volume of $100 \mathrm{ml}$ (containing cefdinir $1 \mathrm{~g}$ and oil in two different concentrations 10 and $15 \% \mathrm{v} / \mathrm{v}$ ) was stirred properly to prepare homogeneous mixtures. The mixture was extruded, using a 20 -gauge syringe needle into $200 \mathrm{ml}$ of gently agitated calcium chloride $(1 \%)$ or aluminum chloride (2\%) solution at room temperature. The resulting beads were allowed to stand in the solution for $24 \mathrm{~h}$ before being separated and washed twice with $500 \mathrm{ml}$ distilled water. The beads were dried at room temperature for $48 \mathrm{~h}$ and were stored in desiccators $[10,11]$.

\section{Characterization of floating beads}

Scanning electron microscopy (SEM)

Morphological examination of the surface and internal structure of the dried calcium alginate beads was carried out using a SEM (JEOL JEM-1200 EX II, Japan) equipped with secondary electron detector at an accelerating voltage of $10 \mathrm{kV}$. The samples were coated with gold to a thickness of about $30 \mathrm{~nm}$ in a vacuum evaporator. The internal structure of beads was examined by cutting them with a steel blade [12]

Determination of bead diameter size

Particle size of the prepared beads was determined using an optical microscope fitted with the stage and an ocular micrometer. Twenty dried beads were measured for calculating the mean diameter of beads. The result is expressed as the mean diameter ( $\mathrm{mm}) \pm$ standard deviation [13].

Drug content and entrapment efficiency

The drug content and entrapment efficiency of prepared beads were determined by the method of extraction of drug present in beads. The dried beads $(100 \mathrm{mg})$ were taken and extracted in $100 \mathrm{~mL}$ of $0.1 \mathrm{~N} \mathrm{HCl}$ (pH 1.2) for $24 \mathrm{~h}$. Then, the dispersion of beads was sonicated for $30 \mathrm{~min}$ and the solution was filtered through a $0.45 \mu \mathrm{m}$ filter. The concentration of drug present in filtrate determined spectrophotometrically at 287 nm (UV-2450, Shimadzu, Japan). Each determination was made in triplicate. The drug content and entrapment efficiency of prepared beads were determined by putting value in the following formula [14].

$$
\text { Drug content }=\frac{\text { Calculated drug content }}{\text { Total amount of beads }} \times 100
$$

Entrapment efficiency $=\frac{\text { Calculated drug content }}{\text { Theoretical drug content }} \times 100$

\section{In vitro buoyancy}

The time interval between the introduction of beads into the dissolution medium and its buoyancy to the top of dissolution medium was taken as floating lag time and floating time was observed visually. The floating abilities of the beads were determined using USP paddle apparatus ( $50 \mathrm{rpm}, 37 \pm 0.2^{\circ} \mathrm{C}, 900 \mathrm{ml}, 0.1 \mathrm{~N} \mathrm{HCl}$ ). 50 beads were placed in the medium; the time to float and duration of floating (floating time) were measured by visual observation. The percentage of floating pellets was calculated by the following equation: [15].

Floating beads $(\%)=$

Number of floating beads at the measure time Initial number of beads
Swelling study

Beads were studied for swelling characteristics. Sample from drug-loaded beads was taken, weighed, and placed in wire basket. Beads were studied for swelling characteristics. Sample from

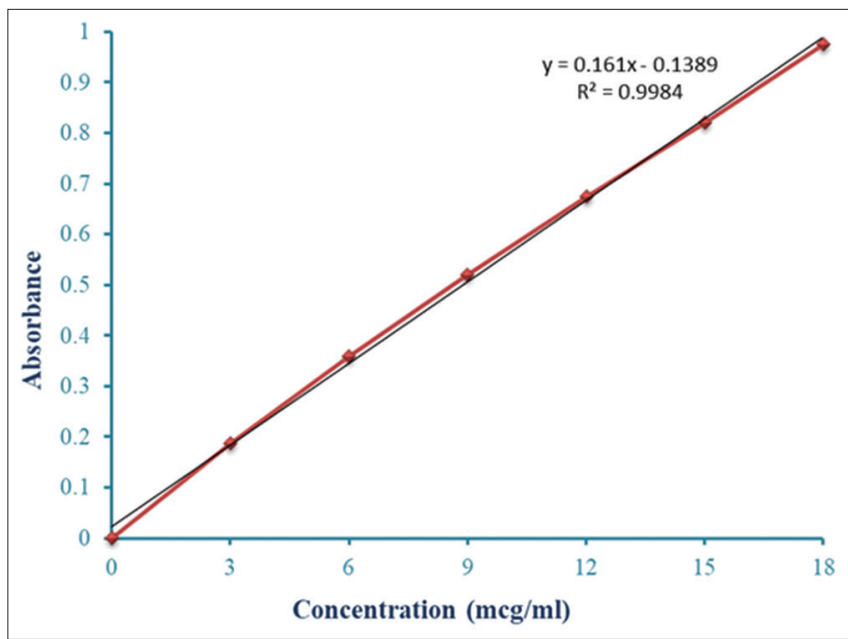

Fig. 1: Calibration curve of cefdinir in $0.1 \mathrm{~N} \mathrm{HCl}$
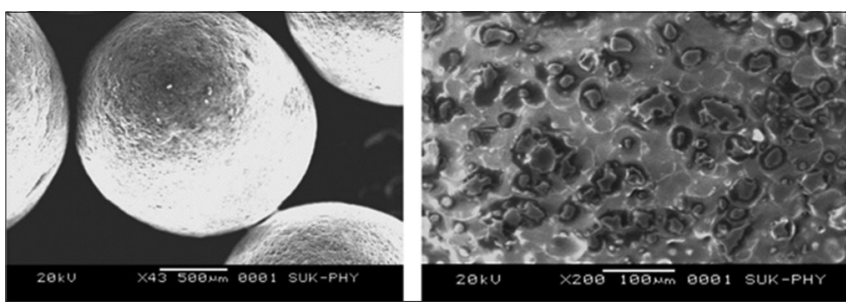

Fig. 2: Scanning electron microscopy of cefdinir-loaded beads
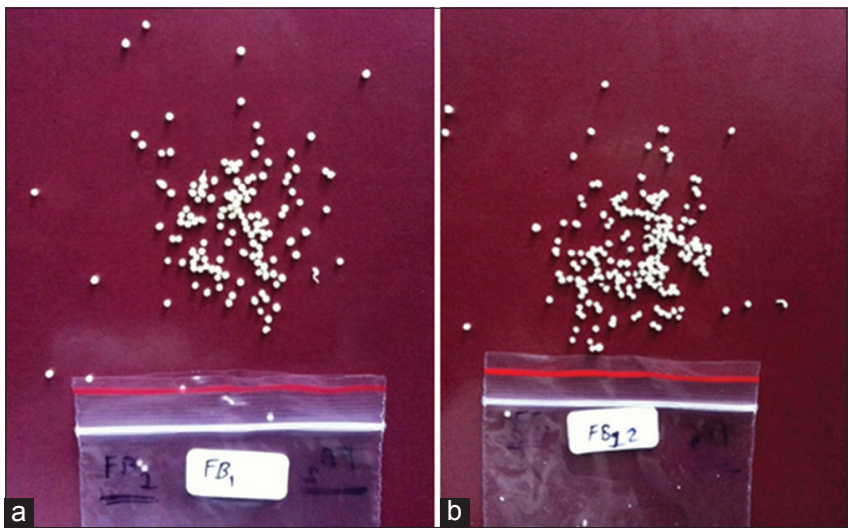

Fig. 3: (a and $b$ ) Photographs of prepared cefdinir beads by emulsion gelation method

Table 1: Formulation batches of floating cefdinir floating beads

\begin{tabular}{|c|c|c|c|c|c|c|c|c|c|c|c|c|}
\hline \multirow[t]{2}{*}{ Ingredients } & \multicolumn{12}{|c|}{ Formulation code } \\
\hline & FB1 & FB2 & FB3 & FB4 & FB5 & FB6 & FB7 & FB8 & FB9 & FB10 & FB11 & FB12 \\
\hline Cefdinir & 1 & 1 & 1 & 1 & 1 & 1 & 1 & 1 & 1 & 1 & 1 & 1 \\
\hline Sodium CMC & - & - & - & - & - & - & - & - & 2.5 & 2.5 & 2.5 & 2.5 \\
\hline Vegetable oil & - & - & - & - & 10 & 10 & 15 & 15 & - & - & 10 & 15 \\
\hline Mineral oil & 10 & 10 & 15 & 15 & - & - & - & - & 10 & 15 & - & - \\
\hline $\mathrm{CaCl}_{2}$ & 1 & - & 1 & - & 1 & - & 1 & - & - & - & - & - \\
\hline $\mathrm{AlCl}_{2}^{2}$ & - & 2 & - & 2 & - & 2 & - & 2 & 2 & 2 & 2 & 2 \\
\hline
\end{tabular}

CMC: Carboxymethyl cellulose 


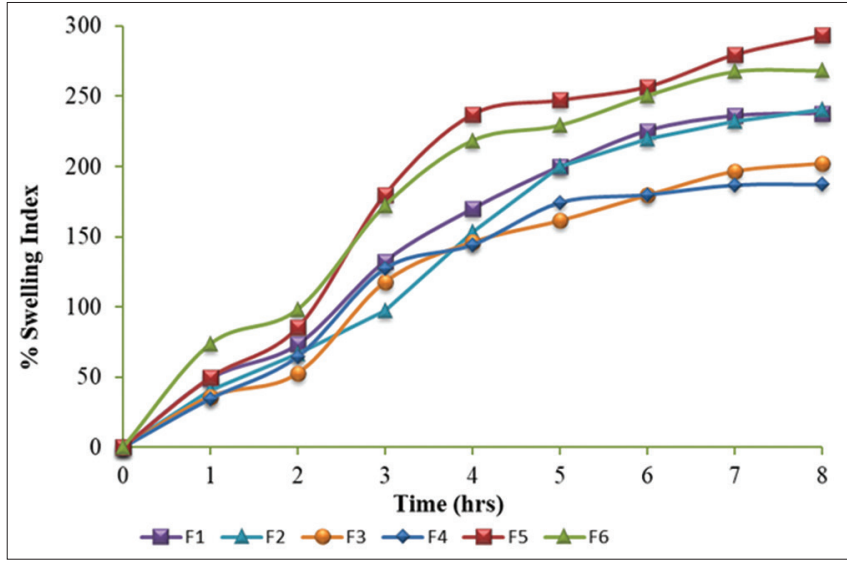

Fig. 4: In vitro swelling data of cefdinir beads (FB1-FB4)

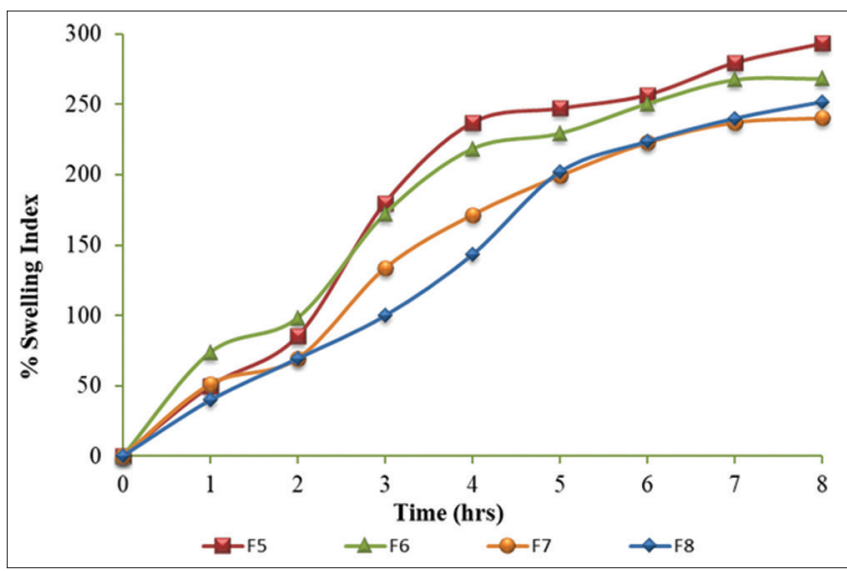

Fig. 5: In vitro swelling data of cefdinir beads (FB5-FB8)

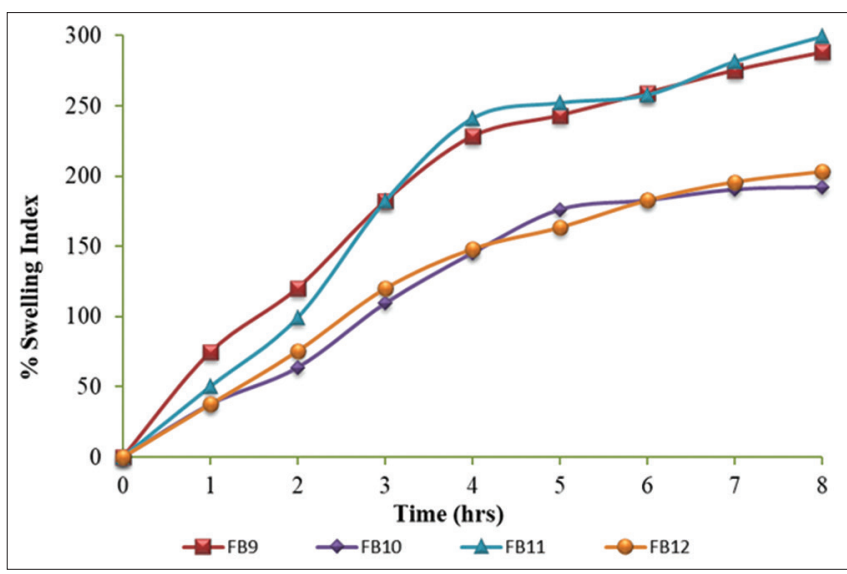

Fig. 6: In vitro swelling data of cefdinir beads (FB9-FB12)

drug-loaded beads was taken, weighed, and placed in wire basket of USP dissolution apparatus II. The basket containing beads was placed in a beaker containing $900 \mathrm{ml}$ of $\mathrm{HCl}$ solution $(\mathrm{pH} 1.2)$ maintained at $37 \pm 0.5^{\circ} \mathrm{C}$. After $12 \mathrm{~h}$, the beads were removed from their respective swelling media and weighed after drying the water on the surface of the beads using filter paper. Then, the swelling index was calculated as percentage using the following formula [16-19].

Swelling index $=\frac{\text { Final wt. of beads }- \text { Initial wt. of beads }}{\text { Initial wt. of beads }} \times 100$
Table 2: Calibration curve of cefdinir in $0.1 \mathrm{~N} \mathrm{HCl}$

\begin{tabular}{ll}
\hline Concentration $(\mathrm{mcg} / \mathrm{ml})$ & Absorbance $($ mean \pm SD) \\
\hline 0 & $0.000 \pm 0.000$ \\
3 & $0.188 \pm 0.004$ \\
6 & $0.358 \pm 0.002$ \\
9 & $0.519 \pm 0.007$ \\
12 & $0.675 \pm 0.003$ \\
15 & $0.821 \pm 0.005$ \\
18 & $0.975 \pm 0.003$ \\
\hline
\end{tabular}

SD: Standard deviation

In vitro drug release studies

Release studies were performed in triplicate using the USP basket method at $100 \mathrm{rpm}$ and $37 \pm 0.5^{\circ} \mathrm{C}$ in $1000 \mathrm{~mL}$ of test medium (i.e., SGF). Approximately, 50 beads were used for each experiment. The samples are withdrawn at specific time interval and assayed spectrophotometrically at the wavelength of maximum absorbance. The percentage of the drug release is calculated with respect to the drug content of the beads The drug content is expressed as the percentage of drug encapsulated in a unit weight of beads. The experiments are carried out in triplicate and the results were averaged [20-24].

\section{RESULTS AND DISCUSSION}

SEM

The surface morphology of prepared beads was studied by SEM. External and internal surfaces of beads formulation FB12 are shown in Fig. 2. The sodium alginate and sodium CMC beads prepared with calcium chloride were spherical, and the beads prepared withaluminum chloride were spherical with tail. External surface was smooth with slightly rougher surface/shrinkage which could be due to drying. In the drug-loaded beads, the internal surface is slightly sponge like which is due to the drug and rate controlling polymer are uniformly dispersed in the polymer matrix. The internal surface of the oil-entrapped beads shows slightly sponge-like nature with little droplets of entrapped oil which imparts buoyancy to the beads. The surface layer of all beads was denser, and hence, in the preparation process, anionic polymer diffused from the droplet core toward the gelling solution (coagulation medium) to form more heterogeneous structure.

The mean particle size of sodium alginate beads FB9-FB12 was between $1.58 \mathrm{~mm}$ and $1.99 \mathrm{~mm}$. Sodium alginate beads were large when compared to sodium CMC due to molecular weight and viscosity. By increasing the oil concentration in the beads, an increase in size of the beads was observed.

\section{Drug entrapment efficiency and floating study}

The percentage yield of each batch was calculated on weight basis with respect to the weight of starting material. The percentage production yield of prepared beads was $81.98 \pm 0.32-96.10 \pm 0.08 \%$ for beads FB1-FB12 as shown in Table 4.

The mean drug entrapment efficiency of sodium alginate beads prepared by emulsion gelation technique of batch FB1-FB12 was between $58.14 \pm 1.87$ and $84.50 \pm 0.33 \%$. Hence, sodium alginate shows higher DEE than sodium CMC. Formulation FB1 shows higher DEE in both the methods $84.50 \pm 0.33 \%$, suggesting that the emulsion gelation methods are effective for the entrapment of cefdinir.

Beads containing sufficient amount of oil FB1-FB12 demonstrated instantaneous floating ability and \% floating was found to be $62.25 \pm 1.40-94.60 \pm 1.05 \%$ (Table 5). Thus, floating ability was found to be directly related to the amount of oil entrapped in the polymer matrix. Furthermore, lower the density of oil, lesser amount of oil is required to float. The beads remained afloat throughout the study period $12 \mathrm{~h}$ and the beads continued to float until $24 \mathrm{~h}$. 
Table 3: Particle size determination and visual analysis of cefdinir beads prepared by emulsion gelation technique (formulations FB1-FB12)

\begin{tabular}{|c|c|c|c|c|}
\hline Formulation code & Particle size $(\mathrm{mm})($ mean $\pm S D)(n=20)$ & Shape & Color & Oil leakage \\
\hline FB1 & $1.94 \pm 0.08$ & Spherical & Off-white & Yes \\
\hline FB2 & $2.02 \pm 0.02$ & Spherical disc & Yellow & Yes \\
\hline FB3 & $2.10 \pm 0.05$ & Spherical & Off-white & Yes \\
\hline FB4 & $1.98 \pm 0.07$ & Spherical disc & Yellow & Yes and high \\
\hline FB5 & $2.08 \pm 0.04$ & Spherical with tail & Off-white & Intermediate \\
\hline FB6 & $1.99 \pm 0.03$ & Spherical disc & Off-white & Yes \\
\hline FB7 & $1.96 \pm 0.02$ & Spherical & Off-white & Yes \\
\hline FB9 & $1.99 \pm 0.03$ & Spherical & White & Intermediate \\
\hline FB10 & $1.67 \pm 0.06$ & Spherical & Off-white & Yes and high \\
\hline FB11 & $1.97 \pm 0.05$ & Spherical & White & Intermediate \\
\hline FB12 & $1.58 \pm 0.02$ & Spherical & Off-white & Yes and high \\
\hline
\end{tabular}

Table 4: Percentage yield and drug entrapment efficiency study of cefdinir beads prepared by emulsion gelation technique (formulations FB1-FB12)

\begin{tabular}{lll}
\hline $\begin{array}{l}\text { Formulation } \\
\text { code }\end{array}$ & $\begin{array}{l}\text { \% yield }(\mathbf{w} / \mathbf{w}) \\
(\mathbf{m e a n} \pm \mathbf{S D})\end{array}(\mathbf{n = 3})$ & $\begin{array}{l}\text { Percentage drug entrapment } \\
(\mathbf{m e a n} \pm \mathbf{S D})(\mathbf{n}=\mathbf{3})\end{array}$ \\
\hline FB1 & $91.37 \pm 0.41$ & $84.50 \pm 0.33$ \\
FB2 & $88.26 \pm 0.57$ & $80.71 \pm 1.78$ \\
FB3 & $81.98 \pm 0.32$ & $79.31 \pm 1.56$ \\
FB4 & $87.91 \pm 0.21$ & $77.08 \pm 0.40$ \\
FB5 & $89.54 \pm 0.13$ & $68.49 \pm 0.87$ \\
FB6 & $96.10 \pm 0.08$ & $61.93 \pm 0.90$ \\
FB7 & $95.08 \pm 0.10$ & $71.28 \pm 0.35$ \\
FB8 & $86.57 \pm 0.36$ & $69.87 \pm 1.14$ \\
FB9 & $87.60 \pm 0.25$ & $58.14 \pm 1.87$ \\
FB10 & $92.32 \pm 0.31$ & $64.42 \pm 1.30$ \\
FB11 & $83.78 \pm 0.29$ & $67.07 \pm 0.67$ \\
FB12 & $94.06 \pm 0.11$ & $81.91 \pm 0.42$ \\
\hline
\end{tabular}

Table 5: In vitro buoyancy study of cefdinir beads prepared by emulsion gelation technique (formulations FB1-FB12)

\begin{tabular}{llll}
\hline $\begin{array}{l}\text { Formulation } \\
\text { code }\end{array}$ & $\begin{array}{l}\text { Floating lag } \\
\text { time }(\mathbf{m i n})\end{array}$ & $\begin{array}{l}\text { Floating } \\
\text { time }(\mathbf{h})\end{array}$ & $\begin{array}{l}\text { Percentage floating } \\
\text { (mean } \pm \text { SD) } \mathbf{( n = 3 )}\end{array}$ \\
\hline FB1 & $<1$ & $>12$ & $86.28 \pm 0.28$ \\
FB2 & $<1$ & $>12$ & $90.36 \pm 0.08$ \\
FB3 & $<1$ & $>12$ & $78.66 \pm 0.78$ \\
FB4 & $<1$ & $>12$ & $84.24 \pm 0.17$ \\
FB5 & $<1$ & $>12$ & $94.60 \pm 1.05$ \\
FB6 & $<1$ & $>12$ & $93.19 \pm 0.34$ \\
FB7 & $<1$ & $>12$ & $93.10 \pm 0.76$ \\
FB8 & $<1$ & $>12$ & $89.90 \pm 1.30$ \\
FB9 & $<2$ & $>12$ & $68.75 \pm 0.78$ \\
FB10 & $<2$ & $>12$ & $62.25 \pm 1.40$ \\
FB11 & $<1$ & $>12$ & $69.89 \pm 1.37$ \\
FB12 & $<2$ & $>12$ & $87.28 \pm 0.90$ \\
\hline
\end{tabular}

Table 6: In vitro swelling data of cefdinir beads (FB1-FB4)

\begin{tabular}{lllll}
\hline Time (h) & \multicolumn{4}{l}{ Swelling index } \\
\cline { 2 - 5 } & FB1 & FB2 & FB3 & FB4 \\
\hline 1 & 49.01 & 40.67 & 36.25 & 34.65 \\
2 & 73.34 & 66.45 & 52.84 & 64.71 \\
3 & 132.5 & 97.22 & 117.82 & 127.35 \\
4 & 169.95 & 153.2 & 146.12 & 144.26 \\
5 & 200.02 & 199.93 & 161.43 & 174.21 \\
6 & 225.47 & 219.55 & 179.48 & 179.84 \\
7 & 236.21 & 231.98 & 196.54 & 186.75 \\
8 & 238.04 & 240.7 & 202.21 & 187.21 \\
\hline
\end{tabular}

In vitro swelling data of cefdinir beads

The swelling index of sodium alginate beads containing vegetable oil (olive oil) as floating agent (FB1, FB2, FB3, and FB4) was 238.04,
Table 7: In vitro swelling data of cefdinir beads (FB5-FB8)

\begin{tabular}{lllll}
\hline Time (h) & \multicolumn{4}{l}{ Swelling index } \\
\cline { 2 - 5 } & FB5 & FB6 & FB7 & FB8 \\
\hline 1 & 49.8 & 73.71 & 51.11 & 39.67 \\
2 & 85.32 & 98.26 & 69.41 & 69.245 \\
3 & 179.96 & 172.2 & 133.5 & 99.72 \\
4 & 237.02 & 218.41 & 171.5 & 143.2 \\
5 & 247.15 & 229.32 & 199.27 & 201.93 \\
6 & 256.74 & 250.41 & 222.7 & 223.55 \\
7 & 279.52 & 267.4 & 237.12 & 239.98 \\
8 & 293.27 & 268.14 & 240.17 & 251.77 \\
\hline
\end{tabular}

Table 8: In vitro swelling data of cefdinir beads (FB9-FB12)

\begin{tabular}{lllll}
\hline Time (h) & \multicolumn{4}{l}{ Swelling index } \\
\cline { 2 - 5 } & FB9 & FB10 & FB11 & FB12 \\
\hline 1 & 74.71 & 37.6 & 50.18 & 37.54 \\
2 & 120.36 & 63.78 & 99.22 & 75.45 \\
3 & 182.2 & 109.35 & 181.96 & 119.84 \\
4 & 228.41 & 145.26 & 241.02 & 148.12 \\
5 & 243.32 & 176.21 & 252.15 & 163.43 \\
6 & 259.41 & 182.84 & 257.74 & 182.8 \\
7 & 275.4 & 190.52 & 281.52 & 195.84 \\
8 & 288.14 & 192.29 & 299.28 & 203.23 \\
\hline
\end{tabular}

$240.7,202.21$, and 187.21, respectively, and for sodium alginate beads containing mineral oil as floating agent (FB5, FB6, FB7, and FB8) was $293.27,268.14,240.17$, and 251.77 , respectively. The swelling index of sodium CMC beads (FB9, FB10, FB11, and FB12) was 288.14, 192.29, 299.28, and 203.23, respectively. The swelling was followed by values in order of vegetable oil >mineral oil.

\section{In vitro drug release data of cefdinir beads}

The percentage cumulative drug release of sodium alginate beads prepared by emulsion gelation method using mineral oil (FB1-FB4) was 76.82, 80.37, 81.81 , and $86.34 \%$, while beads prepared by emulsion gelation method using vegetable oil (FB5-FB8) was 64.61, 69.74,and 80.56\%, respectively, at the end of $12 \mathrm{~h}$ and sodium CMC beads (FB9-FB12) show $84.56,92.58,82.42$, and $94.68 \%$, respectively, at the end of $12 \mathrm{~h}$. Hence, increase the concentration of gas forming agent or oil concentration, increase the percentage cumulative drug release was observed. Percentage cumulative drug release was followed by value in order of sodium alginate >sodium CMC. Furthermore, it was observed that polymers, sodium alginate and sodium $\mathrm{CMC}$, show delayed release up to $12 \mathrm{~h}$.

The stability data are represented in Table 13, and the stability study was performed for selected formulation FB12 for 3 months, suggesting that FB12 the formulation were stable, with no physical change and also the floating ability, DEE and cumulative $\%$ drug release, was not significant changed. 
Table 9: In vitro drug release data of cefdinir beads (FB1-FB4)

\begin{tabular}{lllll}
\hline \multirow{2}{*}{ Time (h) } & \multicolumn{4}{l}{ Cumulative \% drug release } \\
\cline { 2 - 5 } & FB1 & FB2 & FB3 & FB4 \\
\hline 1 & 6.6 & 7.26 & 7.92 & 8.58 \\
2 & 8.25 & 9.44 & 10.63 & 11.82 \\
3 & 12.68 & 12.98 & 15.28 & 18.58 \\
4 & 18.12 & 23.14 & 24.16 & 27.18 \\
5 & 28.94 & 30.12 & 31.3 & 36.48 \\
6 & 36.72 & 39.46 & 42.2 & 44.94 \\
7 & 46.88 & 48.22 & 50.56 & 52.9 \\
8 & 55.76 & 58.18 & 62.6 & 67.02 \\
9 & 62.36 & 68.02 & 69.68 & 73.34 \\
10 & 68.58 & 72.64 & 74.7 & 78.76 \\
11 & 73.33 & 76.5 & 79.67 & 82.88 \\
12 & 76.82 & 80.37 & 81.81 & 86.34 \\
\hline
\end{tabular}

Table 10: In vitro drug release data of cefdinir beads (FB5-FB8)

\begin{tabular}{lllll}
\hline Time (h) & \multicolumn{4}{l}{ Cumulative \% drug release } \\
\cline { 2 - 5 } & FB5 & FB6 & FB7 & FB8 \\
\hline 1 & 5.9 & 6.26 & 6.62 & 6.98 \\
2 & 9.92 & 10.98 & 11.04 & 12.1 \\
3 & 11.74 & 13.8 & 15.86 & 17.92 \\
4 & 20.28 & 22.82 & 27.36 & 31.9 \\
5 & 29.56 & 32.12 & 36.68 & 43.24 \\
6 & 33.12 & 38.23 & 43.34 & 48.45 \\
7 & 51.94 & 50.02 & 58.1 & 60.18 \\
8 & 56.86 & 59.23 & 65.6 & 67.97 \\
9 & 64.61 & 69.74 & 74.87 & 80.56 \\
10 & 69.25 & 74.14 & 79.03 & 83.92 \\
11 & 76.51 & 77.5 & 82.49 & 88.48 \\
12 & 77.28 & 82.08 & 86.88 & 91.68 \\
\hline
\end{tabular}

Table 11: In vitro drug release data of cefdinir beads (FB9-FB12)

\begin{tabular}{lllll}
\hline Time (h) & \multicolumn{5}{l}{ Cumulative \% drug release } \\
\cline { 2 - 5 } & FB9 & FB10 & FB11 & FB12 \\
\hline 1 & 6.98 & 7.32 & 3.21 & 5.38 \\
2 & 9.8 & 14.88 & 10.46 & 12.61 \\
3 & 16.82 & 18.9 & 14.24 & 15.96 \\
4 & 27.12 & 33.4 & 24.64 & 32.98 \\
5 & 38.23 & 44.39 & 32.31 & 46.87 \\
6 & 48.02 & 49.76 & 42.9 & 54.55 \\
7 & 54.23 & 61.98 & 46.68 & 63.5 \\
8 & 65.74 & 69.47 & 60.55 & 76.73 \\
9 & 74.14 & 81.78 & 69.98 & 82.2 \\
10 & 77.5 & 84.92 & 74.73 & 89.42 \\
11 & 82.08 & 89.38 & 78.2 & 92.34 \\
12 & 84.56 & 92.58 & 82.42 & 94.68 \\
\hline
\end{tabular}

\section{CONCLUSION}

Multiparticulate gastroretentive hydrogel beads of cefdinir were formulated with sodium alginate and sodium CMC by emulsion gelation method using olive oil/castor oil. The beads were evaluated for surface morphology, bead size, entrapment efficiency, floating characteristics, in vitro swelling, in vitro drug release, and stability studies. The prepared beads had a different size and the percentage entrapment efficiency of the drug. The SEM study shows that beads are spherical in shape. Comparing all the formulations, formulation FB12 was considered as optimized formulation which shows \% yield $94.06 \pm 0.11$, \% floating $87.28 \pm 0.90$, in vitro drug release $94.68 \%$, and also stable in stability

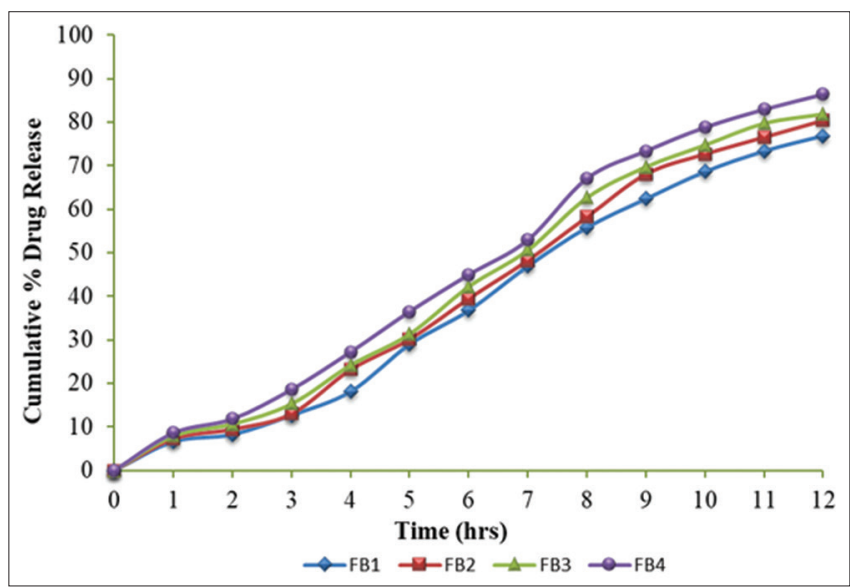

Fig. 7: In vitro drug release data of cefdinir beads (FB1-FB4)

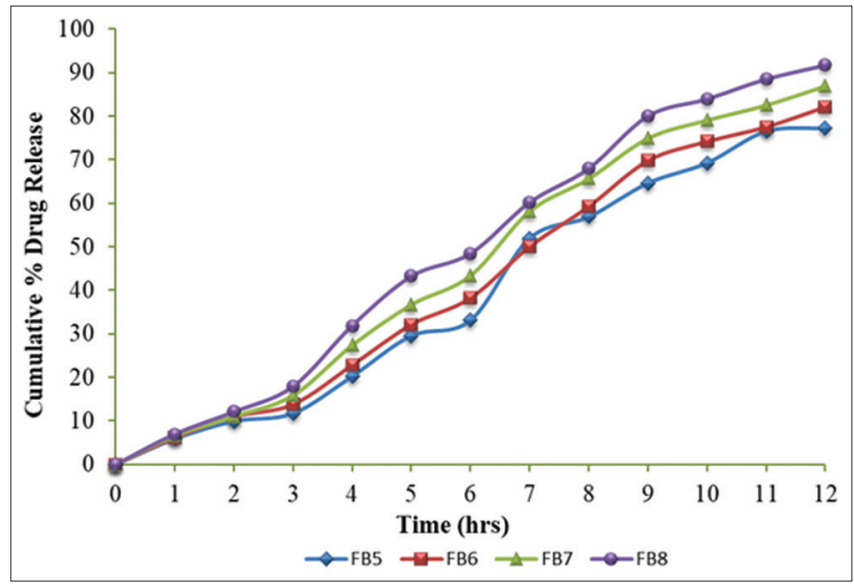

Fig. 8: In vitro drug release data of cefdinir beads (FB5-FB8)

Table 12: In vitro release data according to various release kinetic models

\begin{tabular}{|c|c|c|c|c|c|}
\hline \multirow[t]{2}{*}{ Formulation code } & \multirow[t]{2}{*}{ Zero order $\left(r^{2}\right)$} & \multirow[t]{2}{*}{ First order $\left(r^{2}\right)$} & \multirow[t]{2}{*}{ Higuchi $\left(r^{2}\right)$} & \multicolumn{2}{|c|}{ Peppas plot } \\
\hline & & & & $\left(r^{2}\right)$ & n-value \\
\hline FB1 & 0.9502 & 0.9160 & 0.9893 & 0.9948 & 1.2613 \\
\hline FB2 & 0.9336 & 0.7540 & 0.9956 & 0.9965 & 1.2138 \\
\hline FB3 & 0.9413 & 0.9970 & 0.9947 & 0.9929 & 1.2934 \\
\hline FB4 & 0.9141 & 0.8952 & 0.9891 & 0.9761 & 1.2934 \\
\hline FB5 & 0.9546 & 0.9527 & 0.9731 & 0.9778 & 1.1889 \\
\hline FB7 & 0.9375 & 0.9928 & 0.9954 & 0.9936 & 1.1961 \\
\hline FB8 & 0.9420 & 0.9866 & 0.9909 & 0.9845 & 1.2754 \\
\hline FB9 & 0.9585 & 0.9810 & 0.9623 & 0.9623 & 1.3621 \\
\hline FB10 & 0.9750 & 0.9636 & 0.9262 & 0.9264 & 1.2364 \\
\hline FB11 & 0.9809 & 0.9612 & 0.9204 & 0.9204 & 1.1547 \\
\hline FB12 & 0.9665 & 0.9690 & 0.9280 & 0.9280 & 1.2067 \\
\hline
\end{tabular}


Table 13: Short-term stability study data of cefdinir-loaded beads (FB1 and FB9)

\begin{tabular}{lll}
\hline Sampling time (months) & FB12 & \\
\cline { 2 - 3 } & \% floating (mean \pm SD) $(\mathbf{n}=\mathbf{3})$ & \% DEE (mean \pm SD) (n=3) \\
\hline 0 & $87.28 \pm 0.90$ & $81.91 \pm 0.42$ \\
1 & $86.05 \pm 0.31$ & $81.42 \pm 0.21$ \\
2 & $87.91 \pm 0.22$ & $81.24 \pm 0.17$ \\
3 & $87.66 \pm 0.14$ & $80.13 \pm 0.08$ \\
\hline
\end{tabular}

SD: Standard deviation

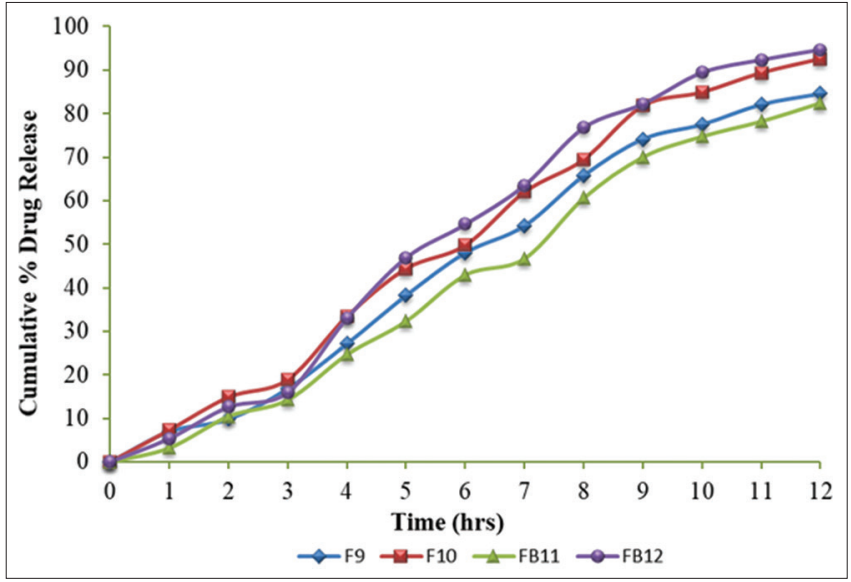

Fig. 9: In vitro drug release data of cefdinir beads (FB9-FB12)

studies. From the findings, it may be concluded that cefdinir-loaded floating beads were successfully prepared and proved to be useful for the prolonged gastric residence of the drug, better bioavailability, and patient compliance for enhanced antimicrobial activity.

\section{AUTHORS' CONTRIBUTION}

The first author carried out experiments. The second author done preformulation study, made arrangement of drug and polymers, and drafted the manuscript.

\section{CONFLICTS OF INTEREST}

Authors declare no conflicts of interest.

\section{REFERENCES}

1. Lopes CM, Bettencourt C, Rossi A, Buttini F, Barata P. Overview on gastroretentive drug delivery systems for improving drug bioavailability. Int J Pharm 2016;510:144-58.

2. Garg R, Gupta GD. Progress in controlled gastroretentive delivery systems. Trop J Pharm Res 2008;7:1055-66.

3. Kare P, Jain D, Jain V, Singh R. Floating drug delivery systems: An overview. J Pharm Res 2010;3:1274-9.

4. Pawar VK, Kansal S, Garg G, Awasthi R, Singodia D, Kulkarni GT. Gastroretentive dosage forms: A review with special emphasis on floating drug delivery systems. Drug Deliv 2011;18:97-10.

5. Guru PR, Nayak AK, Sahu RK. Oil-entrapped sterculia gum-alginate buoyant systems of aceclofenac: Development and in vitro evaluation. Colloids Surf B Biointerfaces 2013;104:268-75.
6. Siraj S, Molvi K. Current trends in gastroretentive floating bioadhesive drug delivery system. Int J Pharm Pharm Res 2016;6:356-67.

7. Nimase PK, Vidyasagar G. Preparation and evaluation of floating calsium alginate beads of clarithromycin. Pharm Sin 2010;1:29-35.

8. Biswas N, Sahoo RK. Tapioca starch blended alginate mucoadhesivefloating beads for intragastric delivery of metoprolol tartrate. Int J Biol Macromol 2016;83:61-70

9. Chandra S, Sowndarya K, Kumar SH, Suresh R, Sangeetha S, Tamilselvan A. Formulation and evaluation studies of floating drug delivery system containing cefdinir antibiotic. Int J Adv Pharm Sci 2018;1:130-76.

10. Ghareeb MM, Issa AA, Hussein AA. Preparation and characterization of cinnarizine floating oil entrapped calcium alginate beads. Int J Pharm Sci Res 2012;3:501-8.

11. Chandra S, Kilimozhi D. Formulation and in-vitro evaluation studies on floating beads of cefaclor by emulsion gelation technique. Indo Am J Pharm Res 2014;4:3365-77.

12. Siraj S, Saad S, Khan GJ, Sharukh P. Formulation and characterization of mucoadhesive microsphere of gliclazide HCL. J Drug Deliv Ther 2018;8:117-25.

13. Pasparakis G, Bouropolous N. Swelling studies and in-vitro release of verapamil from calcium alginate and alginate chitosan beads. Int $\mathrm{J}$ Pharm 2002;3:34-42.

14. Varshosaz J, Tabbakhian M, Zahrooni M. Development and characterization of floating microballoons for oral delivery of cinnarizine by a factorial design. J Microencapsul 2007;24:253-62 .

15. Shweta P. Formulation and evaluation of garlic powder loaded floating matrix tablet. Int J Pharm Pharm Sci 2019;11:17-22.

16. Hari BN, Brahma RA, Samyuktha RB. Floating drug delivery of nevirapine as a gastroretentive system. J Young Pharm 2010;2:350-5.

17. Singhal P, Kumar K, Pandey M, Saraf SA. Evaluation of acyclovir loaded oil entrapped calcium alginate beads prepared by ionotropic gelation method. Int J Chem Tech Res 2010;2:2076-85.

18. Sriamornsak P, Sungthongjeen S, Puttipipatkhachorn S. Use of pectin as a carrier for intragastric floating drug delivery: Carbonate salt contained beads. Carbohydr Polym 2007;67:436-45.

19. Yellanki SK, Nerella NK. Stomach-specific drug delivery of riboflavin using floating alginate beads. Int J Pharm Pharm Sci 2010;2:160-3.

20. Chaturvedi S, Sharma PK, Visht S, Tyagi S, Comparison of emulsification and ionic gelation method of preparation of mucoadhesive microsphere. Pharm Innov 2012;1:1-10.

21. Piyakulawat P, Praphairaksit N, Chantarasiri N, Muangsin N. Preparation and evaluation of chitosan/carrageenan beads for controlled release of sodium diclofenac. AAPS Pharm Sci Tech 2007;8:E1-11.

22. Bhattarai RS, Dhandapani NV, Shreshtha A. Drug delivery using alginate and chitosan bead: An overview. Chron Young Sci 2011;2:192-96.

23. Singhal P, Tomar A, Goel K, Pandey M, Saraf SA. Preparation and evaluation of stomach-specific ion tropically emulsion gelled alginate beads of tinidazole. Pharm Lett 2010;2:272-82.

24. Hemant J, Madhuri T. Formulation development and evaluation of gastro-retentive dosage form of atazanavir sulphate. Int J Pharm Pharm Sci 2018;10:60-70 